\title{
Focal reduction of villous blood flow in early indomethacin enteropathy: a dynamic vascular study in the rat
}

\author{
D A Kelly, C Piasecki, A Anthony, A P Dhillon, R E Pounder, A J Wakefield
}

\begin{abstract}
Background-Oral indomethacin causes villous shortening, microvascular damage, and distortion, which might induce mucosal ischaemia and necrosis.

Aims-In order to determine the early events in indomethacin induced jejunal injury we examined the temporal relations between morphological damage and changes in villous blood flow following indomethacin.

Methods-In anaesthetised rats, mid jejunal villi were exteriorised in a chamber and observed by fluorescence microscopy. Blood flow in surface capillaries was calculated from velocities and diameters. Indomethacin was applied by both luminal and intravenous routes for 90 minutes, after which the animal was perfusion fixed and the villi were processed for histological examination. Control animals received intravenous or luminal bicarbonate (1.25\%).

Results-Blood flow slowed in individual villi at 20 minutes, and progressed to complete stasis (in another group) by 45 minutes. Histological examination at 20 minutes revealed microvascular distortion, but no villous shortening: crypt depth:villous height ratios were 0.356 $(0.02)$ in test and $0.386(0.01)$ in surrounding villi $(p>0.5)$. At stasis, the villi under study showed epithelial clumping and were shortened: crypt depth:villous height ratios were $0.92(0.2)$ in test and $0.42(0.06)$ in surrounding villi $(p<0.02)$. Vehicle alone had no effect on either blood flow or histology.

Conclusions-Focal slowing of villous blood flow and microvascular distortion precede villus shortening and epithelial disruption, and indicate that damage to surface microvasculature is an early event in indomethacin induced mucosal injury in this model.

(Gut 1998;42:366-373)
\end{abstract}

Keywords: indomethacin; jejunum; villi; microcirculation; endothelium; microthrombi

Compared with the relatively common and well recognised gastroduodenal complications of non-steroidal anti-inflammatory drugs (NSAIDs), the incidence of more distal intestinal complications is lower and has not been studied in detail. This is due, in part, to the difficulty in accessing the more distal areas of the gastrointestinal tract. However, lesions beyond the duodenum have been associated with NSAIDs for more than 20 years, mostly in the form of case reports. ${ }^{1}$ NSAIDs have been shown to cause small bowel inflammation, and the passage of cells/proteins into the gut lumen. ${ }^{23}$ Macroscopic damage and histological inflammation have been confirmed by both enteroscopic observation ${ }^{45}$ and post mortem studies. ${ }^{6}$

Rat models have been used widely to study mechanisms involved in NSAID induced ulceration. These mechanisms include contraction of mucosal elements, changes in local villous microcirculation, ${ }^{7-9}$ and decreased prostaglandin synthesis. ${ }^{10}{ }^{11}$ Stratification of epithelium, smooth muscle prominence, villous shortening, and microvascular endothelial swelling in the jejunal mucosa are early preulcerative histological features of NSAID injury, occurring prior to neutrophil recruitment. ${ }^{12} 13$ We hypothesised that villous shortening and endothelial swelling interrupt villous blood flow, resulting in ischaemic injury. This idea is supported by studies showing that NSAIDs and vascular occlusion ${ }^{14-17}$ all cause mucosal lesions. NSAIDs have also been shown to reduce blood flow in the duodenal mucosa. ${ }^{18}$

Although these studies provide some clues to the earliest structural lesions of NSAID enteropathy in this model, they do not resolve the temporal relationship between changes in mucosal blood flow and the putative contraction of mucosal elements that results in villous shortening. This study was designed to try to resolve the question of whether vascular changes either precede, coincide with, or occur after villous contraction and mucosal distortion. The dynamic and histomorphometric techniques used in this study allowed for both continuous observation and recording of villous blood flow, plus instantaneous fixation for histology as changes occurred.

\section{Materials and methods \\ ANIMALS}

Female Sprague-Dawley rats (150-200 g) were obtained from BK Universal Ltd (Oldbrough, Hull, UK), and kept under standardised conditions for food, light, and temperature. Female rats were used in preference to male rats because pilot experiments showed that they produced less mucus, enabling clearer visualisation of vessels for measuring purposes. 
SURGICAL PROCEDURE

Rats were anaesthetised with intraperitoneal urethane $1.5 \mathrm{~g} / \mathrm{kg}$ (Merck Ltd, Lutterworth, Leics, UK) and body temperature was maintained at $37(0.5)^{\circ} \mathrm{C}$ using a homoeothermic blanket and a rectal thermometer (Harvard, Edenbridge, Kent, UK). A cannula was inserted into the left external jugular vein. Tracheostomy was performed and an endotracheal tube inserted. A polyethylene cannula was inserted in the left carotid artery and connected to a pressure transducer (Devices, Welwyn Garden City, Herts, UK) for monitoring mean arterial pressure. Through a right sided laparotomy a mid jejunal loop was exteriorised and a $2 \mathrm{~cm}$ section opened along the antimesenteric border using diathermy. The loop was bathed in Krebs-Hensleit solution at $37^{\circ} \mathrm{C}$, in a perspex observation chamber. A 1 $\mathrm{ml}$ water bath was placed onto the mucosa of the opened loop using micromanipulators. This prevented solutions applied to the mucosa from mixing with the Krebs-Hensleit buffer (fig 1).

To provide a clearer view of villous vessels it was necessary to remove mucus carefully from the surface by gentle touching (not wiping) with cotton wool every 30 minutes. The villous microcirculation was viewed by incident fluoresence microscopy and recorded by video for later analysis; at appropriate moments the intestine was fixed by perfusion fixation for subsequent histological analysis.

FLUORESCENCE MICROSCOPY

As the presence of epithelium and mucus prevented clear observation of vascular flow, both plasma and erythrocytes were labelled fluorescently. Erythrocytes from an age and sex matched donor animal were labelled with fluorescein isothiocyanate (FITC) (Sigma Chemical Co. Ltd, Poole, Dorset, UK) following the method of Sarelius and Duling, ${ }^{19}{ }^{20}$ and injected at a circulating fraction of approximately $10 \%$. Normal rheological behaviour of such erythrocytes in vivo in the rat has been confirmed. ${ }^{20}$ Plasma was labelled with FITCdextran (molecular weight 150 000) $4.4 \mathrm{mg} / \mathrm{kg}$. Although both fluoresce green, red cells were easily distinguished from plasma as they fluoresced with a much greater intensity.

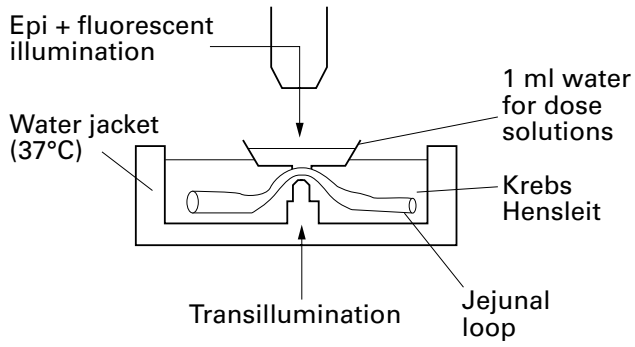

Figure 1 Apparatus used for in vivo microscopy. The water jacket is attached to the side of the animal and a loop of jejunum exteriorised and placed on an observation peg. A small water bath is then placed using micromanipulators onto the mucosal surface of the jejunum and test solutions placed into this bath.
BLOOD FLOW RECORDING AND MEASUREMENT

The apparatus has been described previously. ${ }^{21-23}$ Incident light fluorescence microscopy was performed using a Zeiss Microscope with a mercury high pressure Osram HBO 100W light source (Burke Analytical, Glasgow, UK). The microscopic picture was captured with a silicone intensified camera (SIT, Panasonic Moonlight), and then recorded on a Sony EV-S9000E Hi-8 video recorder (Greenham Video, London, UK), for off line analysis. Blood flow was calculated from velocity and diameter as described by Pries. ${ }^{24}$ All measurements were made in the arcade artery at the tip of a villus. Villi between vasa recta on the mesenteric margin were chosen because this area is most prone to lesions. ${ }^{12}{ }^{1325}$ Blood flow was recorded at one, five, and 10 minutes and every five minutes thereafter until blood flow either stopped or 1.5 hours had elapsed. To avoid deleterious effects of light on the vasculature, ${ }^{26}$ preparations were exposed to fluorescent light for only 60 seconds at each time point.

Two techniques were used to measure red blood cell velocity: frame by frame analysis, a manual reference method, which is a highly accurate but labour intensive technique; and flying spot analysis, a combined manual and electronic method. ${ }^{27}$ Velocity measurements were made five times at each time point and averaged.

On comparing flying spot with frame by frame analysis, flying spot was subject to a variation of up to $25 \%$. Therefore, in experiments where the earliest slowing of blood flow was to be measured, frame by frame analysis was used to ensure a high degree of accuracy. Flying spot analysis was used to measure large changes in blood flow in indomethacin induced lesions, where the flow gradually slows to a stop. Blood vessel diameters were measured using a videometric line drawn across the vessel, and an average taken from four measurements.

\section{HISTOLOGY}

At the earliest visible changes in villous blood flow, and selected time points thereafter, animals were perfusion fixed with $10 \%$ formol saline injected into the beating heart until the mesenteric and serosal vessels had cleared of blood. The observed villus was marked with a suture, and the jejunal section removed and fixed by immersion overnight in $10 \%$ formol saline. The marked villus was then isolated using a stereomicroscope. Two sections of intestine $4 \mathrm{~cm}$ distal and $4 \mathrm{~cm}$ proximal to the observed area were removed and fixed in the same manner. Fixed tissues were processed into paraffin wax, cut into $3 \mu \mathrm{m}$ sections and stained with haematoxylin and eosin.

The crypt depth:villous height ratio was measured, using an eye piece graticule, in the observed villus which exhibited slowing or stasis and compared with surrounding villi in which blood circulation had not slowed.

CONFOCAL MICROSCOPY

Following perfusion fixation and marking, the villus under examination was isolated by 


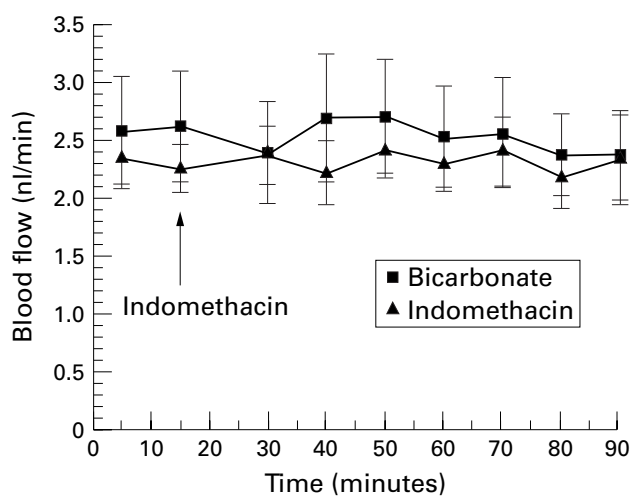

Figure 2 Effect of either luminal or intravenous indomethacin $\left(100 \mathrm{\mu g} / \mathrm{ml}, 2.8 \times 10^{-4} \mathrm{M}\right)$ and bicarbonate control $(0.034 \%)$ on jejunal villous blood flow. Each point expressed as mean (SEM) of five rats $(p=0.9, N S)$.

dissection and mounted in OCT (BDH, Poole, Dorset, UK), and then imaged on a laser scanning confocal microscope MRC-600 (Bio-Rad, Hemel Hempstead, Herts, UK). Villi were cut into $10 \mu \mathrm{m}$ sections on a cryostat (Bright Instruments Ltd, Huntington, UK): others were examined whole.

\section{EXPERIMENTAL GROUPS}

The model was designed, firstly, to evaluate and correlate early changes in flow with microscopic injury at early time points and, secondly, to mimic the effect of oral indomethacin in our previous experiments in rats. In view of enterohepatic cycling of indomethacin, the intestines are exposed to both luminal and systemic challenge following an oral dose of the drug, therefore the drug was given both luminally and systemically. In our previous studies we used 15 $\mathrm{mg} / \mathrm{kg}$ orally which produced consistent ulceration. ${ }^{12}$ Although this dose is high and not relevant to human therapeutic dosing, it provides a reliable and reproducible model for study. A preliminary pharmacokinetic study showed that an oral dose of $15 \mathrm{mg} / \mathrm{kg}$ resulted in concentrations of approximately $100 \mu \mathrm{g} / \mathrm{ml}$ $\left(2.8 \times 10^{-4} \mathrm{M}\right)$ in plasma and $100 \mu \mathrm{g} / \mathrm{ml}(2.8 \times$ $10^{-4} \mathrm{M}$ ) in luminal contents (unpublished data), hence we adopted a dosing regimen comprising $100 \mu \mathrm{g} / \mathrm{ml}$ luminally plus $15 \mathrm{mg} / \mathrm{kg}$ intravenously. In order to determine the influence of route of exposure, three dosing

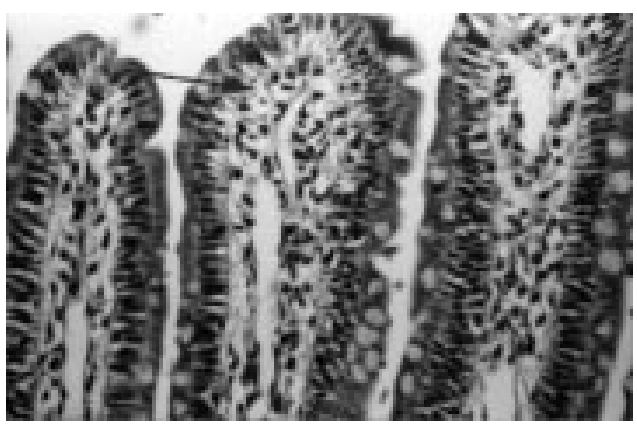

Figure 3 Normal jejunal villous tip from a rat which received luminal indomethacin $\left(100 \mu \mathrm{g} / \mathrm{ml}, 2.8 \times 10^{-4} \mathrm{M}\right)$ and was perfusion fixed 90 minutes after dosing. Subepithelial capillaries are cleared of blood (arrow) indicating no vascular occlusion/blockage, with good preservation of villous architecture. Haematoxylin and eosin, original magnification $\times 250$. groups were compared: luminal alone; intravenous alone; and luminal and intravenous combined. Experimental groups were as follows.

Surgical group

In order to examine the effects of surgical manipulation alone on the intestines, a $2 \mathrm{~cm}$ section of jejunum was diathermied along the antimesenteric border, and removed for histology.

\section{Group 1}

Initially, we sought to ascertain that blood stasis was a feature of more advanced mucosal lesions induced by oral indomethacin (Sigma Chemical Co. Ltd, Poole, Dorset, UK). Group 1 rats received control oral bicarbonate $(1.25 \%)$ given six or four hours prior to mucosal observation $(n=5)$. Group $1 b$ rats received oral indomethacin $(15 \mathrm{mg} / \mathrm{kg})$ dissolved in $1.25 \%$ bicarbonate vehicle $(1 \mathrm{ml}$ per $250 \mathrm{~g}$ body weight), six and four hours prior to mucosal observation ( $\mathrm{n}=5$ per time point).

\section{Group 2}

Group 2 animals were control rats given luminal bicarbonate solution $(0.034 \%)$ alone $(n=5)$. In group 2a, luminal indomethacin 100 or $200 \mu \mathrm{g} / \mathrm{ml}$, dissolved in $0.034 \%$ bicarbonate, was applied to the mucosa $(n=5$ per dose).

\section{Group 3}

Group 3 animals were control rats given an intravenous bolus of bicarbonate solution $(1.25 \%)(n=5)$. In group 3a, indomethacin (15 or $30 \mathrm{mg} / \mathrm{kg}$ bolus) was administered intravenously through the jugular cannula ( $n=5$ per dose).

\section{Group 4}

Group 4 animals were control rats given combined luminal bicarbonate solution $(0.034 \%)$ and intravenous bicarbonate $(1.25 \%)(n=5)$. Group 4a rats were given combined luminal $(100 \mu \mathrm{g} / \mathrm{ml})$ and intravenous indomethacin (15 $\mathrm{mg} / \mathrm{kg})(\mathrm{n}=5)$.

\section{Group 5}

In animals receiving both intravenous and luminal indomethacin (group 4a), slowing of blood flow progressed to focal vascular stasis. This was not observed in other groups. Therefore, in order to evaluate histomorphometric changes at earlier times, when blood flow was slowing down, group 5 animals received combined luminal and intravenous indomethacin (as group 4a); the experiment was terminated by perfusion fixation at the moment slowing of blood flow was first observed microscopically. Blood flow changes were recorded videomicroscopically for later measurement $(\mathrm{n}=5)$.

\section{STATISTICS}

Blood flow and crypt depth:villous height ratio were compared in normal and test villi using the Mann-Whitney U test; an associated probability of $5 \%$ or less was considered significant. 


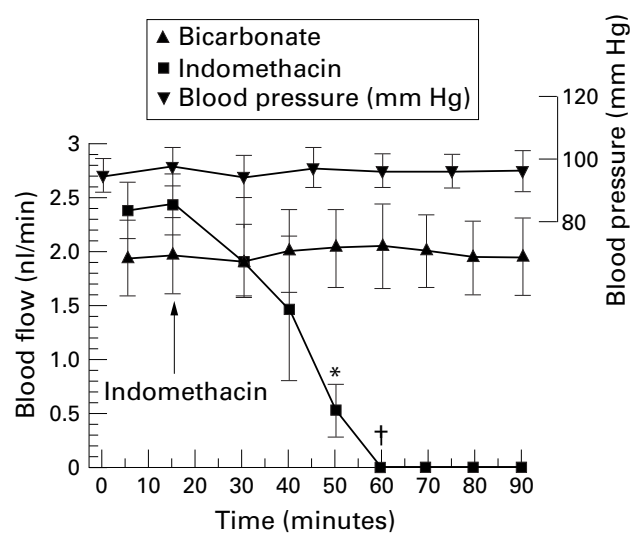

Figure 4 Effect of a combined intravenous and luminal dose of indomethacin $\left(100 \mu \mathrm{g} / \mathrm{ml}, 2.8 \times 10^{-4} \mathrm{M}\right)$ and bicarbonate control on jejunal villous blood flow. Each point expressed as mean (SEM) of five rats. ${ }^{\star} p<0.02$, $t p<0.005$.

\section{Results}

SURGICAL GROUP

Diathermy of the antimesenteric margin of the jejunum removed five rows of villi adjacent to the cut edge, leaving the remaining bowel unaffected.

GROUP 1

Oral vehicle ( $1.25 \%$ bicarbonate, group $1 \mathrm{~b})$ produced no macroscopically visible changes in the mucosa, and microscopic observation showed normal villous morphology throughout. In contrast, four hours after oral indomethacin (group 1a), focal macroscopic lesions were seen from both serosal and
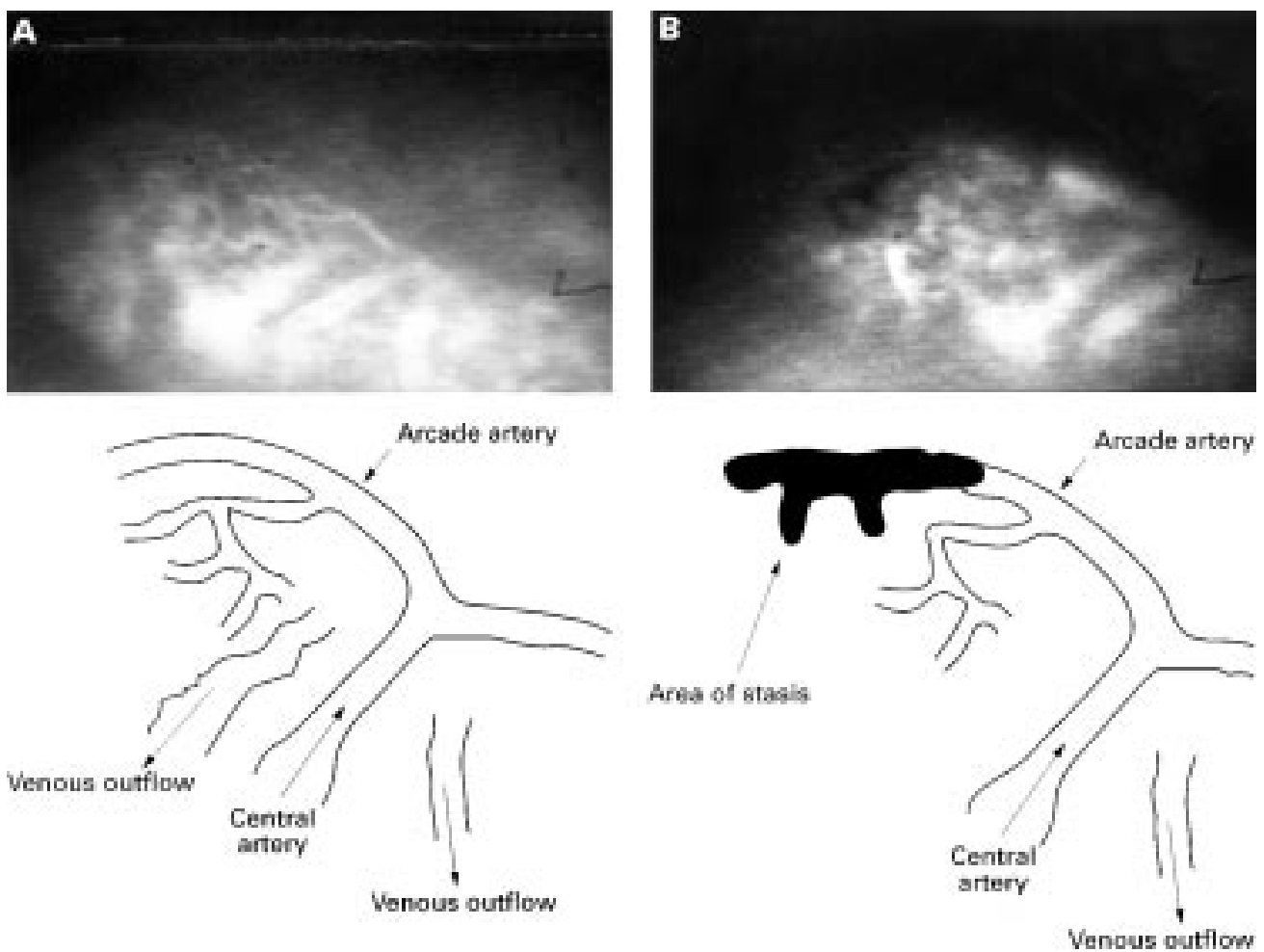

mucosal surfaces. All lesions occurred on the mesenteric aspect, between vasa recta, and appeared as translucent brown patches. Videomicroscopically, villi at the site of these lesions appeared flattened and mucosal blood flow was absent. Histological examination revealed necrosis of the upper third of affected villi.

When examined six hours after indomethacin, lesions were similar to those seen at four hours except that they had become haemorrhagic. Histological examination showed necrosis of the upper third of the affected villi, as at four hours. In surrounding areas of mucosa, blood flow seemed normal, and villi were histologically normal.

GROUPS 2 AND 3

Blood flow (fig 2) and histology were not altered after luminal or intravenous bicarbonate given as control. In groups $2 \mathrm{a}$ and $3 \mathrm{a}$, neither luminal $(100 \mu \mathrm{g} / \mathrm{ml})$ indomethacin nor intravenous indomethacin alone (15 and 30 $\mathrm{mg} / \mathrm{kg}$ ) altered villous blood flow for up to 1.5 hours (fig 2), and histological examination at this time point showed that villi were normal (fig 3). However, $200 \mu \mathrm{g} / \mathrm{ml}$ indomethacin given luminally resulted in a gradual stepwise slowing of flow within 20 minutes which progressed to stasis by 45 minutes. Histologically villi showed typical preulcerative changes.

GROUP 4

In group 4, combined luminal and intravenous bicarbonate had no effect on blood flow for up

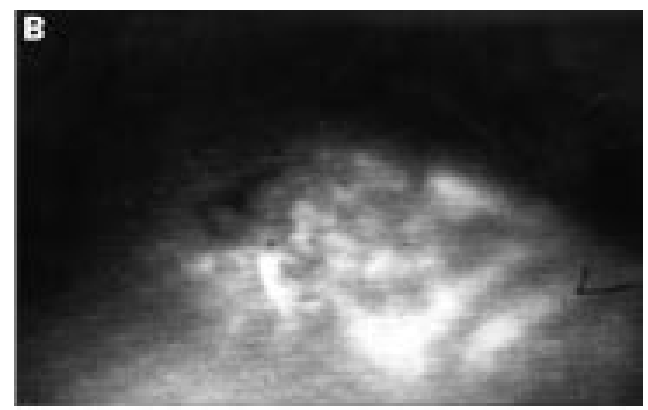

Venous outtiow

Figure 5 (A) Video image obtained from a normal in vivo villus prior to application of indomethacin; the vasculature is highlighted with FITC-dextran in the plasma. Bottom left: line diagram showing the vascular anatomy of the villus in A. Notice the central artery ascending the centre of the villus and dividing at the tip as a T junction to form the arcade artery. This runs along to the left along the tip to supply the left half of the villus, and along the right tip for the right half of the villus. (B) The same villus after application of indomethacin: the darkened area in the upper left half is an area of blood stasis; this is shown more clearly in the line drawing. 

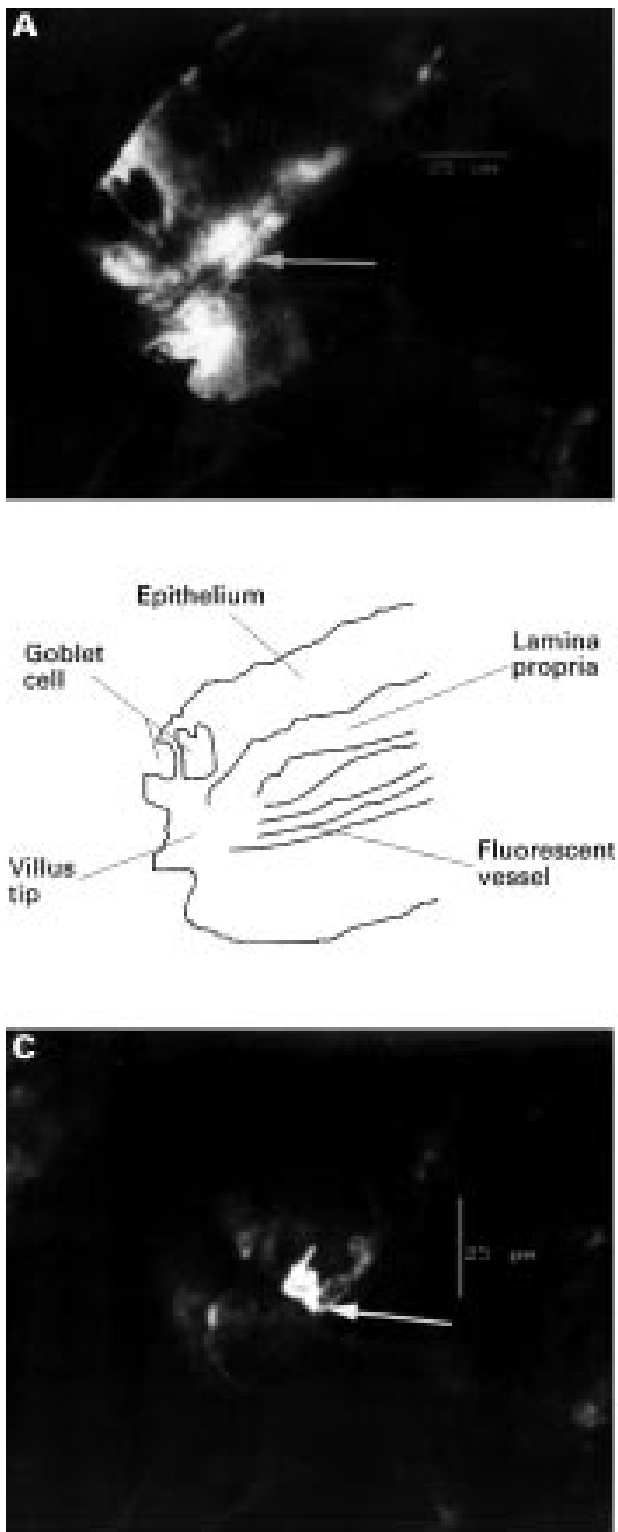

Epithelium at

villus tip
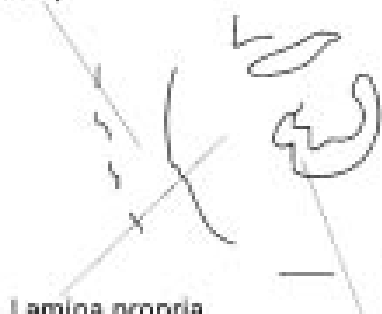

Lamina propria

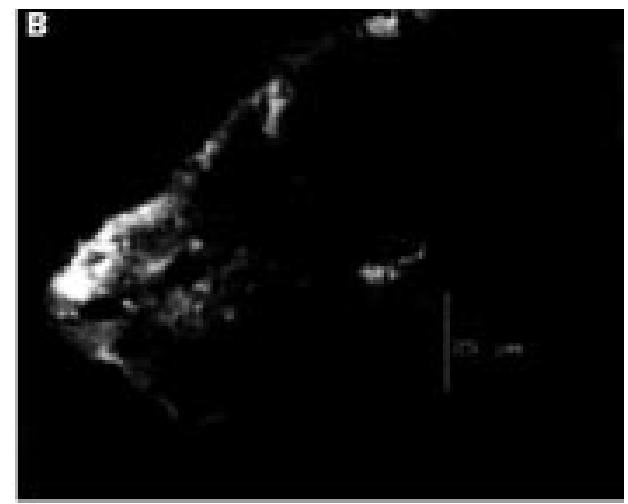

Fluorescent band of mucus

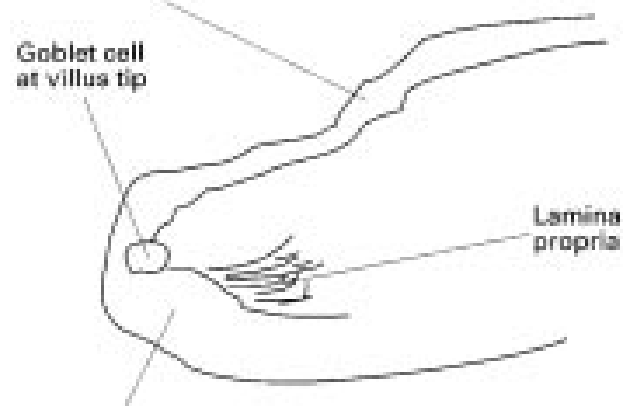

Epithelfum

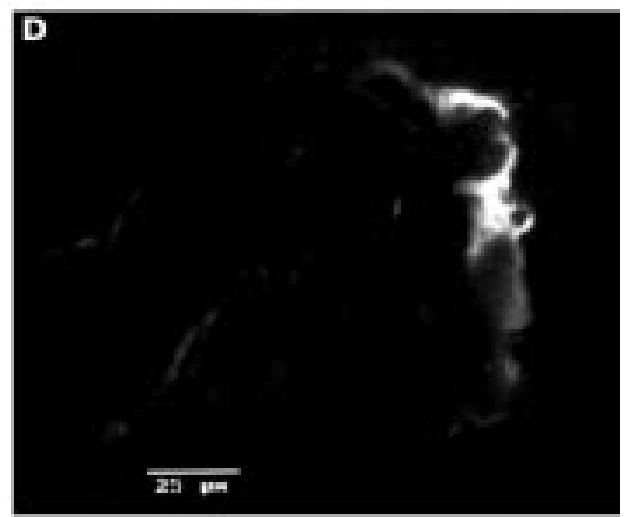

Fluorescent ares of mucus at villus tip

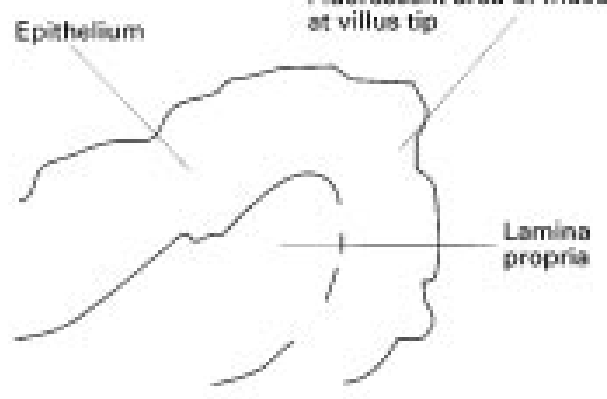

Figure 6 (A) An isolated villus from rat jejunum after combined indomethacin, taken from the left half of the villus which showed stasis and vessel hyperfluorescence (arrow), at which point the villus was perfuse fixed; the area of fluoresence to the left of this vessel is epithelium; original magnification $\times 600$. This is more clearly seen in the line drawing. (B) Image from other right side of the villus which had normal flow and no fluorescence except for surface mucus; original magnification $\times 600$. This is more clearly shown in the line drawing. (C) Transverse confocal image of an isolated villus from rat jejunum after combined luminal $\left(100 \mu \mathrm{g} / \mathrm{ml}, 2.8 \times 10^{-4} \mathrm{M}\right)$ and intravenous $(15 \mathrm{mg} / \mathrm{kg})$ indomethacin, and perfusion fixed as blood flow slowed at 30 minutes. Image is taken from the right side of the villus which exhibited slowing of flow and

hyperfluorescence of the arcade artery (arrow), which is surrounded by epithelium showing slight fluoresence due to surface mucus; original magnification $\times 600$. This is more clearly shown in the line drawing. (D) The left side of this villus which maintained normal flow. The only fluorescence again comes from surface mucus on the epithelium; original magnification $\times 600$. This is more clearly shown in the line drawing. 


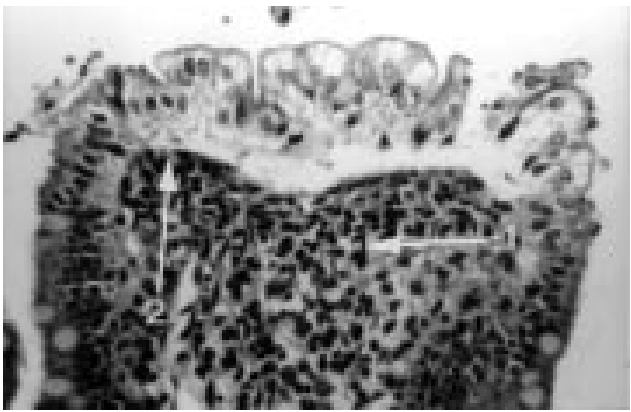

Figure 7 Villous tip from rat jejunum showing blood stasis after combined luminal $\left(100 \mu \mathrm{g} / \mathrm{ml}, 2.8 \times 10^{-4} \mathrm{M}\right)$ and intravenous $(15 \mathrm{mg} / \mathrm{kg}$ ) indomethacin. The surface epithelium is beginning to lift and fall away from the lamina propria. There is contraction of surface smooth muscle cells manifest by prominent contractile elements (arrow 1) causing occlusion of surface vessels (arrow 2); there is also degeneration of the lamina propria; original magnification $\times 250$.

to 90 minutes (fig 4 ) or on the histology. In group $4 \mathrm{a}$, using combined intravenous and luminal administration of indomethacin at the lower doses, blood stasis occurred first in the arcade artery of single villi within 45 minutes of dosing (fig 5); around this focus of vascular stasis, adjacent villi exhibited only slowing of blood flow ( $n=5, p<0.02$; fig 4$)$. In villi exhibiting vascular stasis, confocal microscopy showed hyperfluorescence that seemed to be localised to the endothelium (fig 6A-B). Histological examination showed that affected villi were shortened, with crypt depth:villous height ratios of $0.92(0.2)$ compared with $0.42(0.06)$ in villi without vascular stasis (Mann-Whitney $\mathrm{U}$ test, $\mathrm{p}<0.05$; table 1 ). Corrugation of epithelial cells (tufting) was also observed in the affected villi as described previously ${ }^{12}$ (fig 7).

\section{GROUP 5}

Prior to stasis, combined luminal and intravenous indomethacin produced a discontinuous stepwise slowing of blood flow, whereby flow stopped briefly in the arcade vessel, and then restarted at a lower velocity followed by another brief period of stasis and restart. This process was repeated with progressively longer periods of stasis and greater reductions in blood cell velocity until complete and permanent stasis occurred. Figure 5 shows the time scale of these velocity changes.

Table 1 Crypt depth ( $\mu \mathrm{m})$ to villous height $(\mu \mathrm{m})$ ratios, and individual measurements—stasis in villous tips

\begin{tabular}{llcc}
\hline & & Control villus & Test villus \\
\hline 1 & Crypt depth & 20.3 & 17.3 \\
& Villous height & 46.9 & 24.7 \\
& Ratio & 0.47 & 0.7 \\
2 & Crypt depth & 17.3 & 19.8 \\
& Villous height & 74.1 & 49.4 \\
& Ratio & 0.23 & 0.47 \\
3 & Crypt depth & 14.8 & 19.7 \\
& Villous height & 32.2 & 14.8 \\
4 & Ratio & 0.46 & 1.3 \\
& Crypt depth & 27.8 & 55.1 \\
& Villous height & 55.1 & 45.6 \\
& Ratio & 0.5 & 1.2
\end{tabular}

The measurements were made from perfusion fixed villi exposed to luminal $(100 \mu \mathrm{g} / \mathrm{ml})$ and an intravenous bolus dose of indomethacin estimated to produce a plasma concentration of $100 \mu \mathrm{g} / \mathrm{ml}$ where blood stasis was observed in the villous tips.

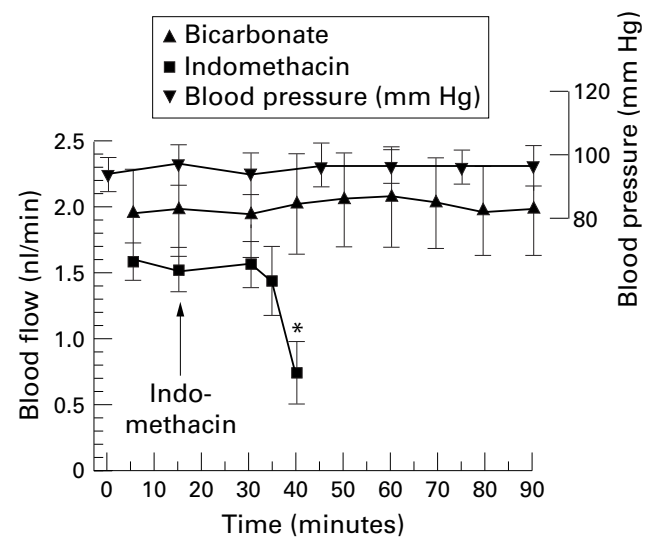

Figure 8 Effect of a combined intravenous and luminal dose of indomethacin $(100 \mu \mathrm{g} / \mathrm{ml})$ and bicarbonate control on jejunal villous blood flow. Each point expressed as mean (SEM) of five rats. ${ }^{\star} p<0.03$.

Table 2 Crypt depth ( $\mu m)$ to villous height $(\mu m)$ ratios, and individual measurements - blood flow in villous tips beginning to slow

\begin{tabular}{llll}
\hline & & Control villus & Test villus \\
\hline 1 & Crypt depth & 24.7 & 20.9 \\
& Villous height & 57 & 55.1 \\
& Ratio & 0.42 & 0.38 \\
& Crypt depth & 22.8 & 19 \\
& Villous height & 57 & 51.3 \\
3 & Ratio & 0.4 & 0.37 \\
& Crypt depth & 20.9 & 19 \\
& Villous height & 51.3 & 47.5 \\
4 & Ratio & 0.41 & 0.4 \\
& Crypt depth & 17.1 & 17.1 \\
& Villous height & 47.5 & 57 \\
5 & Ratio & 0.36 & 0.3 \\
& Crypt depth & 20.9 & 19 \\
& Villous height & 60.8 & 57 \\
& Ratio & 0.34 & 0.33
\end{tabular}

The measurements were made from perfuse fixed villi exposed to luminal $(100 \mu \mathrm{g} / \mathrm{ml})$ and an intravenous bolus dose of indomethacin estimated to produce a plasma concentration of $100 \mu \mathrm{g} / \mathrm{ml}$ where blood flow in the villous tips was beginning to slow.

Slowing was first noticed 20 minutes after exposure to indomethacin in a small focus within a single villus (fig 8 ) originating consistently in the arcade artery along the villus tip, three quarters of the way between the centre and edge of the leaf shaped villus. In addition hyperfluorescence occurred in this segment of the vessel as blood flow began to slow (figs 6C-D). At the moment slowing was first evident microscopically, and later confirmed by velocity measurements, the gut was fixed by vascular perfusion. Histological examination of these tissues showed slight microvascular distortion and epithelial stratification, but no villous shortening at this stage; mean crypt depth:villous height ratios in test villi were $0.356(0.02)$ and $0.386(0.01)$ in surrounding villi with normal circulation ( $\mathrm{n}=5$, MannWhitney U test, $\mathrm{p}<0.2$, NS; table 2 ).

MEAN ARTERIAL BLOOD PRESSURE

Blood pressure remained constant throughout all experiments and was not affected by either surgery or indomethacin (shown on relevant figures).

\section{Discussion}

In previous studies, oral indomethacin resulted in histological villous shortening, infiltration by 
inflammatory cells, stratification of epithelium, and buckling of small and large villous vessels within two hours of administration. ${ }^{12}{ }^{13}$ These changes, particularly buckling of vessels, suggested that a reduction/cessation of blood flow within villi may be involved in the development of subsequent ulceration.

Correlating indomethacin induced changes in villous blood flow with simultaneous histomorphometric changes has enabled us to show that focal microvascular changes and endothelial hyperfluoresence are some of the first demonstrable events, occurring before villous shortening. This study was limited in that only morphological rather than biochemical events were studied. Nevertheless, although significant prostaglandin reductions concomitant with microvascular damage have been reported one hour after indomethacin, ${ }^{13}$ we could only speculate that this reduction in prostaglandins occurs at our much earlier time point of 20 minutes. This is a difficult problem to resolve in view of the highly focal nature of the vascular changes, where local and subtle cyclooxygenase changes may not be detected in increased tissue homogenates for example.

The histological abnormalities, seen at the earliest stage of detectable change in blood flow, were slight distortion of the vessel, epithelial stratification, and retention of fluorescent label at the level of the vascular endothelium (after washing out the vessels during perfusion fixation).

The fact that slowing of flow occurs progressively over the first 30 minutes of exposure to indomethacin suggests that the preulcerative histological features of villous shortening, stratification of epithelium, and smooth muscle prominence, ${ }^{12}$ follow blood flow changes and may be a consequence of diminished blood flow, and not vice versa as we originally suggested. $^{12}$

We have reported that a stepwise slowing of blood flow occurs, as opposed to a uniform and gradual slowing of flow. We are unable to explain this phenomenon; it could not be due to transient vasoconstriction since narrowing would have been evident at videomicroscopy. However, the gradual slowing can be explained if indomethacin is damaging vascular endothelium. This is suggested by hyperfluoresence of the vessel wall seen as soon as blood flow begins to slow, especially as this fluorescence cannot be flushed away by vascular perfusion. This damage may be a type of endothelial permeability, whereby labelled plasma leaks into endothelial cells, but does not pass through them and out into the surrounding lamina propria. Indomethacin may modify endothelial structural integrity and function, perhaps causing swelling. Further studies of the effects of indomethacin on endothelium, and of the intestinal lesion at this early stage are in progress.

The localisation of lesions has been a matter of interest. ${ }^{25}$ At 24 hours rats exposed to oral indomethacin exhibited full thickness lesions localised to the mesenteric margin of the jejunum. Studies at earlier time points, ${ }^{25}$ showed a further localisation within the mesenteric bor- der, with lesions lying only between vasa recta, avoiding the areas overlying these vessels, and our current observations confirm this. Firstly, these areas may be especially susceptible to the vascular effects of indomethacin; secondly, anatomical studies of jejunal vascular anatomy show a paucity of blood vessels between vasa recta ${ }^{25}$; and thirdly, indomethacin has also been shown to reduce mesenteric blood flow. ${ }^{28}{ }^{29}$ These three factors may reduce blood flow to villi in these areas, independently of a luminal effect. However, if this were the case, we should have detected reduced flow occurring in several villi rather than in a single vessel in a small part of a single villus.

The failure to recognise any general reduction in mucosal flow may be due to reduced mesenteric flow producing shunting of intestinal blood flow away from the muscle layers towards the mucosa in order to maintain the integrity of the mucosa as a whole. This would explain why we failed to observe any reductions in whole villi. It would be of interest in the future to correlate reduction in mesenteric inflow with the manifestation of blood stasis in single villi.

Why does the lesion start at a single villus in a single vessel at the tip? There are no clear answers at present for this observation; the endothelial hyperfluorescence suggests damage to the luminal surface of endothelial cells, in turn suggesting an intravascular factor. However there was no gross alteration of blood viscosity at the site of slowing of blood flow; if this had been the case, we would have observed concentration of the fluorescent red cells (an electron microscopy study of endothelium is strongly indicated here). Regarding predisposition for the tip of the villus, we speculate that as mucus is continually secreted from the base of the villus and is removed from the tip by passing contents, the base of the villus has a lower contact with luminal indomethacin compared with the tip, where the lesion first occurs. Another consideration is that older epithelial cells at the tip may be more permeable to indomethacin, leading to exposure of the underlying vessel to the drug.

In summary, focal slowing of villous blood flow is directly linked with histological distortion of surface microvasculature and is therefore an early event in indomethacin induced ulceration. Cessation of blood flow follows later, leading to villous shortening, and ultimately necrosis and ulceration. While it is unlikely that indomethacin induced ulceration is the product of a single factor, this study indicates that focal vascular factors at the villous tip may be more significant than have hitherto been recognised. Since this work shows that the initial structural lesion occurs in only a portion of the villous arcade artery, this early lesion merits study in greater detail. It would also be useful to verify the events highlighted here with other NSAIDs in the intestines.

This work was supported by GlaxoWellcome plc (UK).

1 Aabakken L, Osnes M. Non-steroidal anti-inflammatory drug-induced disease in distal ileum and large bowel. Scand f Gastroenterol 1989;24(suppl 163):48-55. 
2 Bjarnason I, Zanelli G, Prouse P, et al. Blood and protein loss via small intestinal inflammation induced by nonsteroidal anti-inflammatory drugs. Lancet 1987;ii:711-4.

3 Bjarnason I, Zanelli G, Smith T, et al. Non-steroidal anti-inflammatory drug-induced intestinal inflammation in humans. Gastroenterology 1987;93:480-9.

4 Morris AJ, Madhok R, Sturrock RD, et al. Enteroscopic diagnosis of small bowel ulceration in patients receiving non-steroidal anti-inflammatory drugs. Lancet 1991;337: 520

5 Morris AJ, Wasson LA, MacKenzie JF. Small bowel enteroscopy in undiagnosed gastrointestinal blood loss. Gut 1992; 33:887-9.

6 Allison MC, Howatson AG, Torrance CJ, et al. Gastrointestinal damage associated with the use of nonsteroidal anti-inflammatory drugs. $N$ Engl f Med 1992;327:749-54.

7 Piasecki C, Anthony A, Pounder RE, et al. Dynamic studies of acute indomethacin-induced enteropathy: rapid and sustained microvascular stasis [abstract]. Gastroenterology 1994;106:A494.

8 Slater C, House SD. Effects of non-steroidal antiinflammatory drugs on microvascular dynamics. Microvasc inflammatory drugs

9 Shimizu T, Igarashi J, Yamashiro Y, et al. Effects of indomethacin on jejunal mucosal blood flow in the infan rat. Eur f Pediatr 1995;154:592-3.

10 Bjarnason I, Smethurst P, Fenn GC, et al. Misoprostol reduces indomethacin induced changes in human smal intestinal permeability. Dig Dis Sci 1989;34:407-11.

11 Morris AJ, Madhok RJ, Capell HA, et al. The effect of misoprostol on enteroscopy-diagnosed NSAID small bowe enteropathy-a retrospective study. Gut 1992;33(supp $1)$ :S9.

12 Anthony A, Dhillon AP, Nygard G, et al. Early histological features of small intestinal injury induced by indomethacin. Aliment Pharmacol Ther 1993;7:29-40.

13 Nygard G, Anthony A, Piasecki C, et al. Acute indomethacin-induced jejunal injury in the rat: early morphological and biochemical changes. Gastroenterology morphological and

14 Svanes K, Ulven A. Gastric ulceration associated with experimental occlusion. Digestion 1977;15:517-25.

15 Whittle B, Kauffman GI, Moncada S. Vasoconstriction Whittle B, Kauffman GL, Moncada S. Vasoconstriction
with thromboxane A2 induces ulceration of the gastric mucosa. Nature 1981;292:472-4.

16 Gerkens JF, Flexner C, Oates JA, et al. Prostaglandin and histamine involvement in the gastric vasodilator action of pentagastrin. F Pharmacol Exp Ther 1977;201:421-6.
17 Gerkens JF, Shand DG, Flexner C, et al. Effect of indomethacin and aspirin on gastric blood flow and acid indomethacin and aspirin on gastric blood flow a
secretion. $\mathcal{F}$ Pharmacol Exp Ther 1977;203:646-52.

18 Taha AS, Angerson W, Nakshabendi I, et al. Gastric and duodenal mucosal blood flow in patients receiving non-steroidal anti-inflammatory drugs-influence of age, smoking, ulceration and Helicobacter pylori. Aliment Pharmacol Ther 1993;7:41-5.

19 Sarelius IH. Microcirculation in striated muscle after acute reduction in systemic hematocrit. Respir Physiol 1989;78:717 .

20 Sarelius IH, Duling BR. Direct measurement of microvessel hematocrit, red cell flux, velocity and transit time. Am $\mathcal{F}$ Physiol 1982;243:H1018-26.

21 Neff M, Metry JM, Frick P, et al. The microvasculature of the small intestinal mucosa of the rat: quantification of haemodynamic effects of topically applied cimetidine, ranitidine, somatostatin and vasopressin. Scand $\mathcal{F}$ Gastroenterol 1985;112:6-11.

22 Knoblauch M, Hollinger C. Microcirculation studies on rat small intestinal villi in vivo. Schweiz Med Wochenschr 1977; 107:1391-9.

23 Hollinger C, Radzyner $M$, Knoblauch $M$. Effects of glucagon, vasoactive intestinal peptide, and vasopressin on villous microcirculation and superior mesenteric artery blood flow in the rat. Gastroenterology 1983;85:1036-43.

24 Pries AR. A versatile video image analysis system for microcirculatory research. Int f Microcirc Clin Exp 1988;7:32745 .

25 Anthony A, Pounder RE, Dhillon AP, et al. Vascular anatomy defines sites of indomethacin ulceration along the mesenteric margin. Gut 1997;41:763-70.

26 Miller FN, Sims DE, Schuschke DA, et al. Differentiation of light-dye effects in the microcirculation. Microvasc Res 1992;44:166-84.

27 Slaf DW, Arts T, Jeurens TJM, et al. Electronic measurement of red blood cell velocity and volume flow in microvessels. Microvasc Res 1990;40:302-16.

28 Feigen LP, King LW, Ray J, et al. Diffferential effects of ibuprofen and indomethacin in the regional circulation of the dog. F Pharmacol Exp Ther 1981;219:679-84.

29 Gaffney GR, Williamson HE. Effect of indomethacin and meclofenate on canine mesenteric and celiac blood flow. Res Commun Chem Pathol Pharmacol 1979;25:165-8. 